\title{
APLIKASI MOBILE PERPUSTAKAAN BERBASIS ANDROID (STUDI KASUS PERPUSTAKAAN STMIK PALANGKARAYA)
}

\author{
M.Haris Qamaruzzaman ${ }^{1}$, Ferdiyani Haris ${ }^{2}$ \\ (Sekolah Tinggi Manajemen Informatika dan Komputer Palangkaraya) \\ Jl. G. Obos No.114 Telp. (0536) 3225515 Fax (0536) 3236933 \\ Manajemen Informatika1' Sistem Informasi ${ }^{2}$ \\ Email : harisqamaruzzaman@yahoo.co.id, sabila006@gmail.co.id
}

\begin{abstract}
Android is an operating system for mobile devices based on Linux, versions of android is ever released Android version 1.1, Android version 1.5 (Cupcake) Android version 1.6 (Donut), the Android version $2.0 / 2.1$ (Eclair), Android Version 2.2 ( Froyo or Frozen Yoghurt), and Android version 2.3 (Gingerbread). There is no problem of this research is to create a mobile application android-based library (library, case studies Palangkaraya Campus). This system aims to help students find the information collections, membership, books being borrowed and never borrowed, change passwords member, information libraries and librarians. The system is made using Eclipse, the Java programming language, PHP and $M y S Q L$ as a media server that is accessed using the application

The methods in this study includes data collection method (observation, literature, and interviews) and analyzed using analysis systems PIECES. Analysis PIECES have 6 (six) phases Performance, Information, Economics, control, efficiency and service.

In this study has been conducted to test black box testing or testing program errors and the result of the program can be run to provide better information.
\end{abstract}

Keywords : Android, Mobile, Server, Eclipse

\section{PENDAHULUAN}

Salah satu perangkat mobile yang paling pesat adalah Handphone dimana hampir setiap orang memilikinya. Handphone yang digunakan sebagai alat komunikasi saat ini sudah lebih dari fungsi dasarnya.

Android sebagai Sistem Operasi berbasis linux yang dapat digunakan di berbagai perangkat mobile. Android memiliki tujuan utama untuk memajukan inovasi piranti telepon bergerak agar pengguna mampu mengeksplorasi kemampuan dan menambah pengalaman lebih dibandingkan dengan platform mobile lainnya.

Bagi perpustakaan STMIK Palangkaraya yang merupakan salah satu pusat ilmu pengetahuan untuk 
mahasiswa STMIK Palangkaraya perangkat mobile berbasis android dibutuhkan sebagai media informasi tentang koleksi yang ada di perpustakaan. Perpustakaan STMIK Palangkaraya memiliki berbagai macam koleksi diantaranya buku pengetahuan, buku bisnis, buku motivasi, jurnal, skripsi/TA, novel dan lainnya. Selain memiliki beberapa koleksi, Perpustakaan STMIK Palangkaraya pun melayani peminjaman buku untuk mahasiswa. Jadi, selain mobile android untuk media informasi, perpustakaan STMIK Palangkaraya membutuhkan sebuah monitoring peminjaman buku, salah satu teknologi yang dapat digunakan adalah SMS gateway.

Maka dari itu, penulis merancang dan membangun aplikasi mobile perpustakaan berbasis android (study kasus perpustakaan STMIK Palangkaraya) diharapkan mampu membantu mahasiswa dalam mencari referensi dan petugas perpustakaan dalam memonitoring peminjam.

\section{KAJIAN TEORI}

Mobile Device

Mobile Device (juga dikenal dengan istilah cellphone, handheld device, handheld computer, "Palmtop", atau secara sederhana disebut dengan handheld) adalah alat penghitung (computing device) yang berukuran saku, ciri khasnya mempunyai layar tampilan (display screen) dengan layar sentuh atau keyboard mini. Dalam hal PDA (Personal Digital Assistant) masukan (input) dan keluaran (output) dikombinasi dalam interface layar sentuh.

\section{Android}

Menurut Nazruddin Safaat H (2011:1), android adalah sebuah sistem operasi untuk perangkat mobile berbasis linux yang mencakup sistem operasi, middleware dan aplikasi. Android menyediakan platform yang terbuka bagi para pengembang untuk menciptakan aplikasi mereka.

\section{SDLC}

Menurut Adi Nugroho (2010 : 2), Pengembangan/rekayasa sistem informasi (system development) dan/atau perangkat lunak (software engine) dapat berarti menyusun sistem/perangkat lunak yang benarbenar baru atau yang lebih sering terjadi, menyempurnakan yang telah ada sebelumnya. 


\section{UML (Unified Modeling Language)}

Menurut Nugroho (2010 : 6) UML adalah 'bahasa' permodelan untuk sistem atau perangkat lunak yang berparadigma 'berorientasi objek'.

$U M L$ adalah sebuah bahasa untuk menentukan, visualisasi, kontruksi, dan mendokumentasikan artifac (bagian dari informasi yang digunakan atau dihasilkan dalam suatu proses pembuatan perangkat lunak. Dapat berupa model, deskripsi atau perangkat lunak) dari sistem perangkat lunak, seperti pada permodelan bisnis dan sistem non perangkat lunak lainnya.

\section{PHP (PHP-Hypertext Preprocessor)}

Menurut M. Rudyanto Arief (2011:43), PHP (PHP-Hypertext Preprocessor) adalah bahasa server-side scripting yang menyatu dengan HTML untuk membuat halaman web yang dimanis. Karena PHP merupa server-side scripting maka sintaks dan perintahperintah PHP akan dieksekusi di server kemudian hasilnya dikirimkan ke browser dalam format HTML.

PHP biasanya dijadikan sebagai module dalam suatu web agar bisa mengeksekusi file-file PHP yang tersedia di web server. PHP dapat berjalan di hampir seluruh platform, open source dan berlicensi GNU Public License (GPL). (Welling, 2001)

\section{Jquery Mobile}

Jquery Mobile adalah sebuah flatform pengembangan dari Jquery. Dengan menggunakan Jquery Mobile, programmer dapat men-depelov berbagai solusi mobile yang bekerja dengan baik diberbagai piranti mobile.

\section{Eclipse}

Menurut Wina Noviana Fatimah (2011:2), Eclipse adalah sebuah IDE (Integrated Development Environment) untuk mengembangkan perangkat lunak dan dapat dijalankan di semua platform (platform-independent).

Berikut ini adalah sifat dari Eclipse:

Multi-platform: Target sistem operasi Eclipse adalah Microsoft Windows, Linux, Solaris, AIX, HP-UX dan Mac OS X.

Mulit-language: Eclipse dikembangkan dengan bahasa pemrograman Java, akan tetapi Eclipse mendukung pengembangan aplikasi berbasis bahasa pemrograman lain seperti $\mathrm{C} / \mathrm{C}++$, Cobol, Python, Perl, PHP, dan lain sebagainya.

Multi-role: Selain sebagai IDE untuk pengembangan aplikasi. Eclipse pun 
bisa digunakan untuk aktivitas dalam siklus pengembangan perangkat lunak seperti dokumentasi, pengujian perangkat lunak, pengembangan web, dan lain sebagainya

\section{METODOLOGI PENELITIAN}

Metodologi yang digunakan pada penelitian ini adalah Model Waterfall. angkah-langkah Waterfall yang digunakan dalam membangun dan merancang Aplikasi mobile perpustakaan berbasis android (studi kasus perpustakaan STMIK Palangkaraya).

Teknik analisa yang terdiri dari :

\section{Analisa data}

Dalam penelitian ini, digunakan analisis data kualitatif dalam menarik kesimpulan dari data yang ada. Artinya peneliti membangun perancangan sistem dari kasus-kasus yang bersifat khusus berdasarkan pengalaman yang nyata (di intansi tempat penelitian), untuk kemudian dirumuskan menjadi model konsep, teori, prinsip, atau definisi yang bersifat umum. Data kuantitatif adalah data berbentuk angka (scoring).

\section{Analisa Sistem}

Analisa sistem menggunakan teknik analisa PIECES, yaitu untuk mengetahui sejauh mana Performa, Informasi yang dihasilkan, Efektifitas, Control (Keamanan), Nilai Ekonomis dan Service (Layanan) dari sistem yang sudah berjalan saat ini.

\section{Perancangan}

Yaitu proses pemecahan masalah yang disertai dengan pemikiran kreatif guna mencapai hasil yang optimal

\section{Implementasi}

Menurut Nurdin Usman, (2004:70) mengemukakan bahwa "implementasi adalah peluasan aktivitas yang saling menyesuaikan". Secara sederhana implementasi bisa diartikan pelaksanaan atau penerapan. Implementasi sistem yang digunakan dalam penelitian ini yaitu Php dan Mysql merupakan sebuah bahasa pemrograman yang bersifat open source, maksudnya pendistribusian programnya disertakan juga kode programnya dan biasanya secara gratis.

Dengan menggunakan PHP script maka maintenance suatu situs web menjadi lebih mudah. Proses update data dapat dilakukan dengan menggunkan aplikasi yang dibuat dengan menggunakan script PHP.

\section{Uji coba system}

Yaitu tahap pengujian sistem yang bertujuan untuk memastikan apakah semua fungsi sistem dalam program 
bekerja dengan baik serta untuk mengetahui apakah sistem dalam program tersebut telah berjalan sesuai dengan apa yang telah dirancang sebelumnya. Pengujian sistem merupakan proses menjalankan dan mengevaluasi sebuah perangkat lunak secara manual maupun otomatis untuk menguji apakah perangkat lunak sudah memenuhi persyaratan atau belum.

\section{Pemeliharaan}

Pemeliharaan adalah kegiatan yang cukup penting dilakukan dalam manajemen operasional. Karena fasilitas yang dimiliki harus dijaga agar dapat digunakan secara kelancaran sehingga proses operasional tidak terganggu. Tujuan pemeliharaan adalah untuk menjaga agar sistem yang ada dapat berjalan sebagaimana mestinya dan juga untuk dapat mengendalikan biaya baik untuk pencegahan maupun perbaikan jika terjadi kerusakan.

\section{HASIL PENELITIAN DAN}

\section{PEMBAHASAN}

\section{Implementasi}

Pada tahap ini penulis akan membuat dan melakukan proses uji coba Sistem dan Program, Manual Program, Manual Instalasi, dan Pemeliharaan aplikasi sehingga dapat dimengerti dengan baik dan diketahui cara penggunaannya.

\section{Tampilan Aplikasi}

Pada tahapan ini akan ditampilkan menu-menu, sub - sub menu dan tombol (button) yang terdapat pada aplikasi ini dan kegunaannya. Penjelasan dari masing - masing penggunaan tersebut dapat dilihat pada gambar 1 dibawah ini:

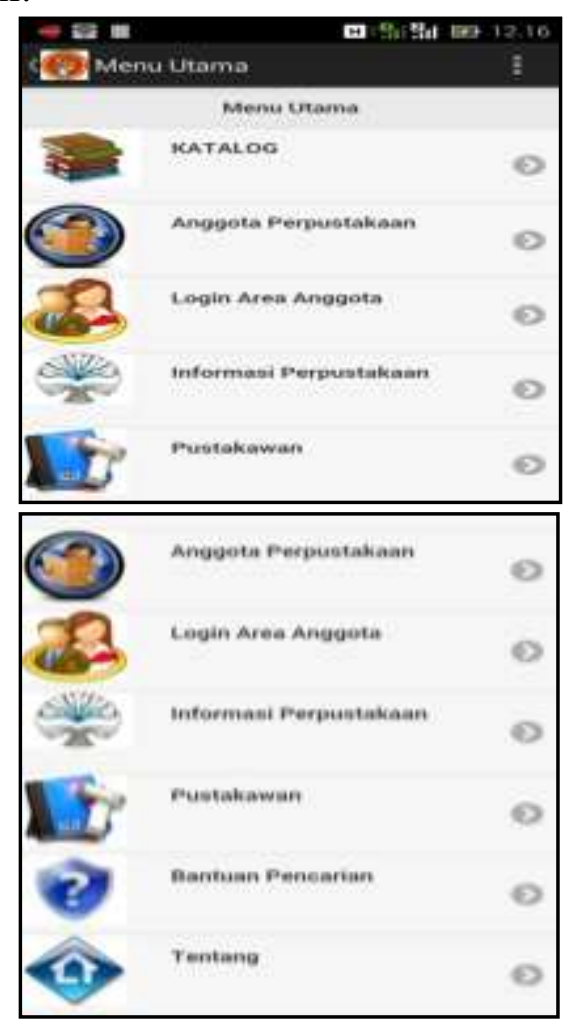

\section{Gambar1. Menu Utama}

Pada gambar menunjukkan bahwa Menu untuk masuk ke tampilan pencarian koleksi perpustakaan.Menu untuk masuk ke tampilan sub menu jurusan dan sub menu daftar anggota perpustakaan. 
Menu untuk masuk ke tampilan sub menu login, sub menu buku yang sedang di pinjam, sub menu buku yang pernah di punjam, sub menu mengubah password, sub menu mengisi kuisioner, dan sub menu menampilkan jawaban kuisioner.

Menu untuk masuk ke tampilan informasi perpustakaan.

Menu untuk masuk ke tampilan informasi pustakawan.

Menu untuk masuk ke tampilan bantuan pencarian.

Menu untuk masuk ke tampilan tentang pembuat aplikasi dan aplikasi.

Menu Katalog

Untuk bisa menampilkan tampilan pencarian dan menampilkan daftar koleksi yang ada di perpustakaan. Pengguna terlebih dahulu memilih menu Katalog kemudian mengisi kata kunci yang ingin di cari dan memilih tombol cari. Untuk lebih jelasnya dapat dilihat pada gambar 2 dibawah ini.

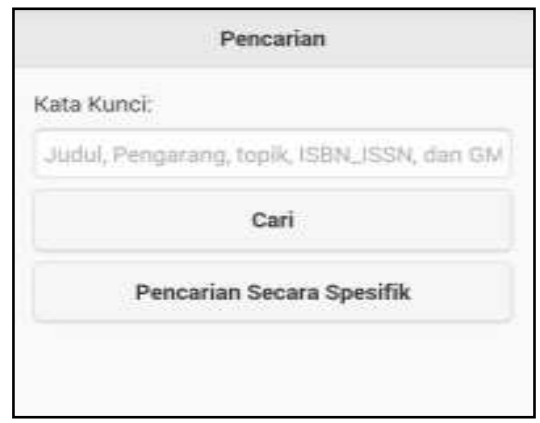

Gambar 2. Menu Pencarian
Pada Gambar 2 terlihat bahwa Edit teks untuk memasukan kata kunci. Kata kunci bisa berupa judul, pengarang, topic, ISBN/ISSN, dan GMD.

Tombol untuk mencari kata kunci yang di masukan.

Tombol untuk menampilkan sub menu pencarian berdasarkan Klasifikasi.

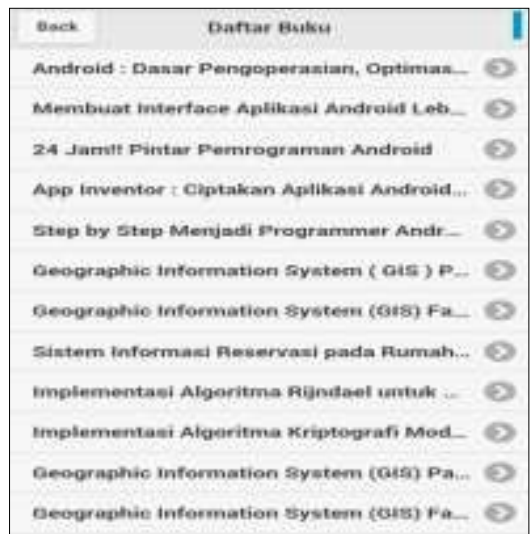

Gambar 3. Tampilan koleksi buku

Pada Gambar 3 terlihat bahwa Tombol untuk kembali pada tampilan sebelumnya.

Listview judul koleksi perpustakaan

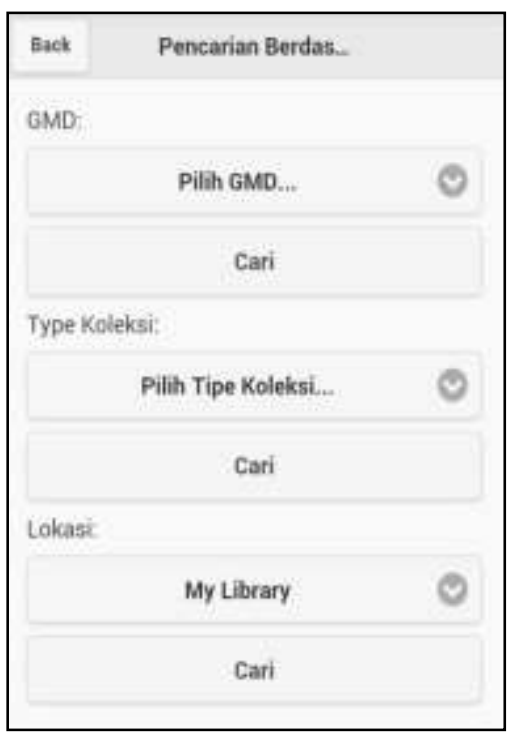

Gambar 4. Pencarian 
Pada gambar 4 dijelaskan bahwa Tombol kembali ke tampilan pencarian secara keseluruhan

Listview GMD yang berisi buku, PKL, PKL TI, PKL SI, PKL SI, Proposal Skripsi, Skripsi TI, Skripsi SI, Tugas Akhir, Jurnal, Majalah, Tabloid, CDROM, E-Artikel, Digital Versatile Disc, E-Book.

Tombol untuk mencari GMD yang dipilih.

Listview tipe koleksi yang berisi reference, textbook, fiction.

Tombol untuk mencari tipe koleksi yang dipilih.

Listview my library yang berisi my library.

Tombol untuk mencari my library yang dipilih.

\begin{tabular}{l} 
O Back Detail Buku \\
Judul : Pemrograman Delphi 8.0 \\
Pengarang : Hendrayudi \\
Penerbit: Yrama Widya \\
Tempat Terbit : Bandung \\
Tahun Terbit : 2008 \\
ISBN_ISSN : $978-979-543-678-2$ \\
Tahun Terbit : 2008 \\
Nomor Panggil : 004 Hen $p$ \\
\hline
\end{tabular}

Gambar 5. Detail Buku
Pada gambar 5 menjelaskan bahwa Tombol untuk kembali pada tampilan sebelumnya.

Informasi detail tentang buku atau koleksi perpustakaan

Menu Informasi Anggota

Untuk bisa menampilkan tampilan daftar nama anggota perpustakaan. Pengguna terlebih dahulu memilih menu informasi anggota kemudian memilih jurusan anggota yang ingin dilihat. Untuk lebih jelasnya dapat dilihat pada gambar 6 dibawah ini.

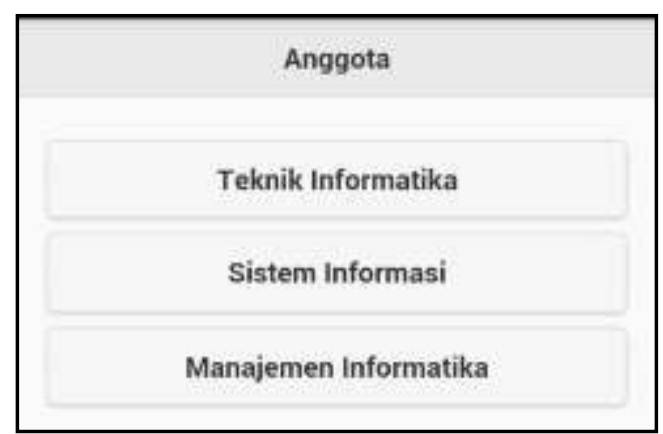

Gambar 6. Menu Anggota

Penjelasan gambar 6 :

Tombol untuk masuk ke tampilan daftar nama anggota jurusan Teknik Informatika.

Tombol untuk masuk ke tampilan daftar nama anggota jurusan Sistem Informasi. Tombol untuk masuk ke tampilan daftar nama anggota jurusan Manajemen Informatika. 
Pada Gambar 7 menjelaskan bawha Tombol untuk kembali ke tampilan sebelumnya.

Listview daftar nama anggota.

\begin{tabular}{|c|c|}
\hline Buck & Teknik Informatika \\
\hline & $\begin{array}{l}\text { Nama: Tri Yoenatan A. Bayan } \\
\text { NiM: Co710802006 } \\
\text { Jurusan: Teknik Informatika } \\
\text { Alamst Ji. Menteng } 25 \\
\text { No_Telp: 0857 } 51975827\end{array}$ \\
\hline & $\begin{array}{l}\text { Nama: I Made Swastika A. } \\
\text { NiM: Co955201049 } \\
\text { Jurusan: Teknik Informatika } \\
\text { Alamat. Ji. Jati Raya III } \\
\text { No_Telp: } 085390390672\end{array}$ \\
\hline & $\begin{array}{l}\text { Nama: Agnes Jeane } \\
\text { NIM: C1055201141 } \\
\text { Jiarusan: Teknik Informatika } \\
\text { Alamat Ji. Lele IV No. } 10 \\
\text { No_Telg: 0821. } 9208.0657\end{array}$ \\
\hline & $\begin{array}{l}\text { Nama: Jimi Kronika } \\
\text { NIM: Co955201002 } \\
\text { Jurusan: Teknik informatika } \\
\text { Alamat Jl, G. Obos } 12 \\
\text { No_Telp: } 082155634420\end{array}$ \\
\hline
\end{tabular}

Gambar 7. Menu Nama Anggota

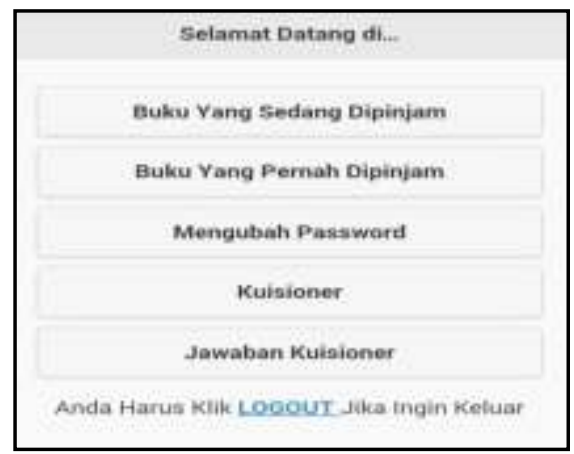

Gambar 8. Menu Keterangan Buku

Penjelasan gambar 8 :

Tombol masuk ke tampilan buku yang sedang dipinjam

Tombol masuk ke tampilan buku yang pernah dipinjam

Tombol masuk ke tampilan mengubah password
Tombol masuk ke tampilan mengisi

kuisioner

Tombol masuk ke tampilan jawaban kuisioner

Tombol logout, logout digunakan untuk keluar dari area anggota

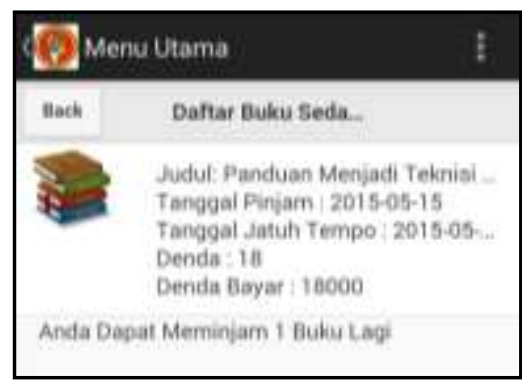

Gambar 9. Daftar Buku

Gambar 9 menjelaskan bawa Tombol untuk kembali ke tampilan yang sebelumnya. Daftar buku sedang dipinjam dan keterangan banyak buku yang masih bisa dipinjam

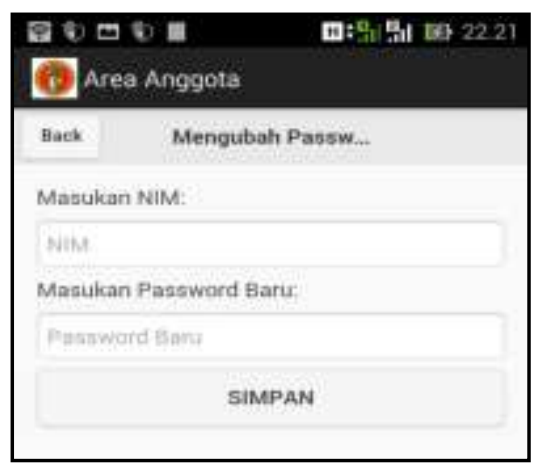

Gambar 10. Area Anggota

Penjelasan gambar 10 :

Tombol untuk kembali ke tampilan yang sebelumnya.

Edit teks untuk memasukan nim. 
Edit teks untuk memasukan password baru.

Tombol untuk menyimpan password baru.

\begin{tabular}{l}
\hline Back Kuisioner \\
Nama: \\
NIM: \\
NIM Pilih Jurusan... \\
Jurusan: \\
$\begin{array}{l}\text { Apakah menurut anda aplikasi ini baik untuk } \\
\text { membantu anda mendapatkan informasi dari } \\
\text { perpustakaan? } \\
\text { Pilih Jawaban... }\end{array}$ \\
$\begin{array}{l}\text { Apakah menurut anda aplikasi ini baik untuk } \\
\text { membantu anda mencari koleksi } \\
\text { perpustakaan? }\end{array}$ \\
Pilih Jawaban...
\end{tabular}

\section{Gambar 11. Menu Kuisioner}

Pada gambar 11 menjelaskan bahwa Tombol untuk kembali ke tampilan yang sebelumnya. Edit teks untuk mengisi nama. Edit teks untuk mengisi nim. Teks View untuk mengisi jurusan.

Pertanyaan kuisioner. Teks view pilihan jawaban. Pilihan jawaban terdiri dari sangat baik, baik, cukup baik, kurang baik dan tidak baik.

Gambar 12 menjelaskan bahwa Tombol untuk kembali ke tampilan yang sebelumnya. Daftar jawaban kuisioner
Menu Informasi Perpustakaan Menu informasi perpustakaan pada aplikasi ini menampilkan informasi mengenai perpustakaan STMIK Palangkaraya. Untuk lebih jelas dapat dilihat pada gambar dibawah ini.

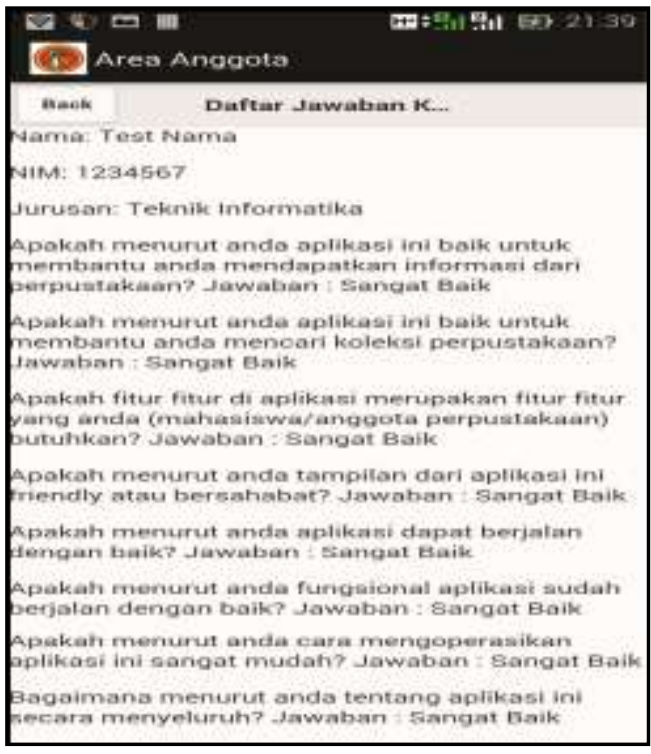

\section{Gambar 12. Menu Jawaban}

\section{Kuisioner}

\begin{tabular}{|c|}
\hline Informasi Perpust. \\
\hline $\begin{array}{l}\text { Alamat Perpuntaicaan di di. A. Obos No. II } \\
\text { Palangkaraya. }\end{array}$ \\
\hline OPENING HOUFS \\
\hline $\begin{array}{l}\text { Hari Senin Kamis : Buka } 08.00 \text { Wis, Istirahat } \\
12.00-13.30 \text { WiB, Tutup } 15.30 \text { Wie }\end{array}$ \\
\hline $\begin{array}{l}\text { Hari Jumat: Buka } 09.00 \text { wise, istirahat } 11.00 \text { - } \\
13.30 \text { Wie, Tutug } 15.30 \text { Wie }\end{array}$ \\
\hline $\begin{array}{l}\text { Hari Sabtu : Buila } 08.00 \text { Wie, istirahat } 12.00 \text { - } \\
13.30 \text { WiB, Tutup } 15.00 \text { WiB. }\end{array}$ \\
\hline KOLEKSI \\
\hline 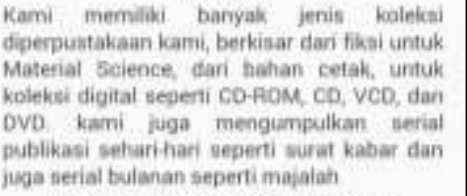 \\
\hline KEEANGGOTAAN PERPUSTAKAAN \\
\hline 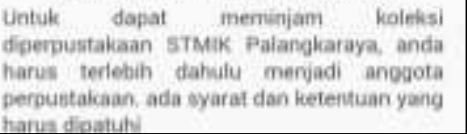 \\
\hline
\end{tabular}

Gambar 13. Info Perpustakaan 
Pada gambar 13 menjelaskan bahwa Tombol kembali, Textview Informasi Perpustakaan. Menu Informasi Pustakawan, Menu informasi pustakawan pada aplikasi ini menampilkan informasi mengenai pustakawan atau petugas perpustakaan STMIK Palangkaraya. Untuk lebih jelas dapat dilihat pada gambar dibawah ini.

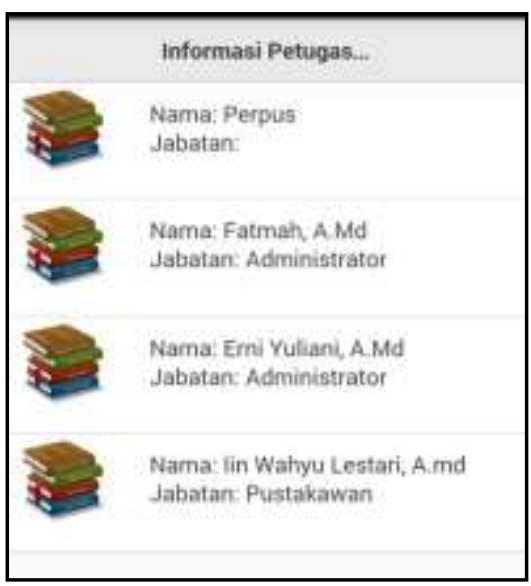

Gambar 14. Info Petugas

Pada gambar 14 menjelaskan Listview untuk daftar nama pustakawan atau petugas Perpustakaan Menu Bantuan Pencarian

Menu bantuan pencarian pada aplikasi ini menampilkan informasi mengenai bantuan pencarian menggunakan aplikasi mobile perpustakaan. Untuk lebih jelas dapat dilihat pada gambar dibawah ini.

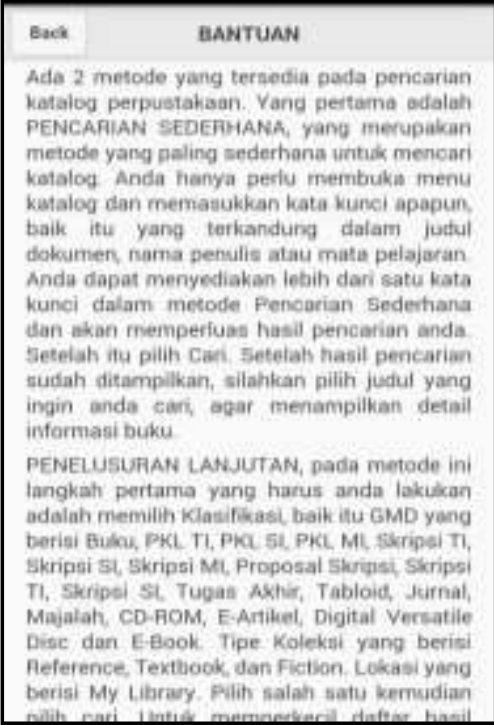

\section{Gambar 15. Bantuan}

Pada Gambar 15 menjelaskan bahwa Tombol untuk kembali pada tampilan sebelumnya. Informasi bantuan pencarian

\section{Uji Coba Aplikasi}

Tahap pengujian ini dimaksudkan untuk menguji apakah aplikasi yang dibuat sudah dapat berjalan dengan baik sesuai dengan tujuan yang ingin dicapai. Jenis pengujian yang akan ditempuh penulis adalah Black Box Testing. Dengan Black Box Testing maka dapat diketahui kesalahan yang terjadi pada aplikasi perpustakaan berbasis android misalnya seperti ketidaksesuaian, kesalahan informasi, serta kesalahan fungsi

Pembahasan

Berdasarkan hasil kuesioner pada tabel dapat ditabulasikan (rekapitulasi data) 
menggunakan skala pengukuran Rating

Scale sebagai berikut :

Jumlah skor kriterium $=($ Skor tertinggi $)$

$\mathrm{x}$ (jumlah pertanyaan) $\mathrm{x}$ (jumlah

responden)

Jumlah skor kriterium $=5 \times 8 \times 15$

$$
=600
$$

Berdasarkan tabel jumlah totalnya adalah = 542 dengan demikian, Aplikasi "Aplikasi Mobile Perpustakaan Berbasis Android (Studi Kasus Perpustakaan STMIK Palangkaraya)" menurut persepsi 15 orang yaitu 542 : $600 \times 100 \%$ dari kriterium yang ditetapkan. Apabila diinterpretasi nilai adalah $90 \%$ terletak lebih dekat dengan daerah baik (B), sedangkan nilai 542 termasuk kategori interval (jarak antara dua nilai) lebih dekat ke baik (B).

Berdasarkan hasil perhitungan kuesioner dengan Skala Likert yang didapat dari responden dan 8 pertanyaan maka didapatkan hasil interpretasi sebesar $90 \%$ atau dengan nilai 542 dari nilai maksimal sebesar 600 , maka dapat disimpulkan bahwa hasil penelitian ini baik dan layak digunakan.

\section{KESIMPULAN}

Berdasarkan uraian yang telah dilakukan sebelumnya, maka dapat diambil beberapa kesimpulan sebagai berikut.

Aplikasi Mobile Perpustakaan Berbasis Android (Studi Kasus Perpustakaan STMIK Palangkaraya) berhasil menampilkan seluruh koleksi dengan pencarian yang menggunakan kata kunci dan klasifikasi.

Anggota dapat melihat buku buku yang sedang dipinjam, pernah dipinjam, dan mengubah password dengan aplikasi Mobile Perpustakaan Berbasis Android (Studi Kasus Perpustakaan STMIK Palangkaraya)

Anggota dapat melihat informasi perpustakaan, pustakawan, dan bantuan pencarian menggunakan aplikasi

\section{SARAN}

Berdasarkan kesimpulan yang telah dikemukan diatas, saran yang dapat diberikan pada penelitian ini adalah sebagai berikut:

Penulis mengharapakan agar pengembang selanjutnya dapat mengembangkan aplikasi ini dari segi jaringan agar tidak hanya menggunakan jaringan LAN namun informasi perpustakaan dapat di akses secara online.

Aplikasi ini tidak bisa menampilkan jumlah ekslempar buku yang sedang dipinjam oleh anggota perpustakaan. 
DAFTAR PUSTAKA

DISDIKPORA Palangkaraya. 2012.

Petunjuk Pelaksanaan Rekrutmen

Calon Kepala Sekolah/

Madrasah. Palangkaraya

Hendi, 2009. Berbagai Aplikasi

Database Dengan Visual Basic

6.0. Elex Media Komputindo, Jakarta.

Kusrini, 2007. Konsep dan Aplikasi SISTEM PENDUKUNG

KEPUTUSAN. Andi, Yogyakarta.
Kusumadewi, Sri dan Sri Hartati. Agus

Harjoko dan Retantyo Wardoyo.2006 . Fuzzy MultiAttribute Decision Making.Graha ilmu, Yogyakarta.

Putra, Indra. 2004. Membuat Aplikasi Program Nyata dengan Visual Basic 6.0. Andi, Yogyakarta

Permendiknas No. 28 Ayat 2 Tahun 2010 Tentang Persyaratan Administrasi 